\title{
PELATIHAN PENGEMBANGAN BAHAN AJAR DIGITAL MENGGUNAKAN WHITEBOARD ANIMATION PADA GURU SMP
}

\author{
Salim', Arvyaty ${ }^{2}$, Kadir $^{3}$, Muhammad Sudia ${ }^{4}$, \\ Rahmad Prajono ${ }^{5}$, Mursidin $\mathrm{T}^{6}$ \\ 1,2,3,4,5 Jurusan Pendidikan Matematika, Fakultas Keguruan dan Ilmu Pendidikan, \\ Universitas Halu Oleo, Kampus Hijau Bumi Tridharma, Anduonohu, Kec. Kambu, Kota Kendari \\ ${ }^{6}$ Jurusan Pendidikan Sejarah, Fakultas Keguruan dan Ilmu Pendidikan, Universitas Halu Oleo, \\ Kampus Hijau Bumi Tridharma, Anduonohu, Kec. Kambu, Kota Kendari \\ 1e-mail: salim@uho.ac.id
}

\begin{abstract}
Abstrak
Tujuan dari kegiatan pengabdian ini adalah untuk meningkatkan kualitas pembelajaran dan kompetensi guru melalui pengunaan bahan ajar digital menggunakan Whiteboard Animation pada sekolah mitra. Sasaran program kegiatan pengabdian ini adalah guru SMP di Kota Kendari berjumlah 20 orang. Metode yang digunakan berupa metode ceramah, tanya jawab, dan simulasi. Hasil dari kegiatan ini menunjukkan: (1) para peserta workshop telah memiliki pengetahuan membuat bahan ajar digital menggunakan whiteboard animation, (2) para peserta workshop telah memiliki bahan ajar digital dengan menggunakan whiteboard animation, dan (3) para peserta workshop telah memiliki pengetahuan dalam membuat dan mengembangkan konten bahan ajar digital menggunakan whiteboard animation.
\end{abstract}

Kata kunci: media pembelajaran, bahan ajar digital, whiteboard animation.

\begin{abstract}
The purpose of this dedication is to improve the quality of learning and competence of teachers through the use of Digital teaching materials using Whiteboard Animation in partner schools. The object of this devotion is the teacher of SMP Negeri 5 Kendari and SMP Negeri 9 Kendari as many as 20 people. The methods used are lecture methods, questions and answers, and simulations. The results of this activity show: (1) Workshop participants have had the knowledge of creating digital teaching materials using Whiteboard animation, (2) The workshop participants have had digital teaching materials using Whiteboard animation, and (3 ) Workshop participants have knowledge in creating and developing digital teaching materials content using Whiteboard animation.
\end{abstract}

Keywords: instructional media, digital teaching materials, whiteboard animation

\section{PENDAHULUAN}

Upaya meningkatkan mutu pendidikan harus dilakukan agar dapat menunjang pembangunan nasional. Upaya tersebut tentunya menjadi tanggung jawab bersama, terlebih bagi semua tenaga kependidikan. Guru merupakan titik sentral dalam pelaksanaan pembelajaran kerena guru merupakan komponen pendidikan yang berhubungan langsung dengan siswa. Sehingga guru menjadi komponen penting dalam meningkatkan mutu pendidikan. Namun dalam upaya 
meningkatkan mutu pendidikan, tentunya banyak hal yang menjadi kendala bagi guru. Hal yang paling sulit adalah menumbuhkan minat belajar pada siswa, padahal minat belajar memiliki pengaruh yang sangat penting dalam keberhasilan pembelajaran. Menurut Karina, Syafrina, \& Habibah (2017), minat memiliki hubungan dengan hasil belajar yaitu minat berperan penting dalam menentukan hasil belajar siswa. Budiwibowo (2016) mengungkapkan bahwa siswa yang tidak memberikan minat terhadap apa yang mereka pelajari maka hasil belajar yang diperolehnya menjadi rendah. Oleh karena itu, hal utama yang harus dilakukan guru dalam upaya meningkatkan mutu pendidikan adalah dengan meningkatkan minat belajar siswa terlebih dahulu.

Guru sebagai pendidik dan pengajar harus mampu menciptakan pembelajaran yang menarik di dalam kelas sehingga para siswa mampu berkonsentrasi dan menaruh minat pada proses pembelajaran. Fakhrurrazi (2018) mengungkapkan bahwa proses pembelajaran merupakan suatu proses yang mengandung serangkaian pelaksanaan oleh guru dan siswa atas dasar hubungan timbal balik yang berlangsung dalam situasi edukatif untuk mencapai tujuan tertentu. Sebagai serangkaian aktivitas yang sengaja diciptakan maka guru dalam hal ini harus merancang metode pembelajaran untuk dapat mencapai tujuan pembelajaran tersebut. Pane \& Dasopang (2017) mengemukakan bahwa penggunaan metode pembelajaran yang bervariasi akan memberikan suasana belajar yang menarik, dan tidak membosankan bagi peserta didik. Akan tetapi, bisa saja penggunaan metode yang bervariasi menjadikan kegiatan belajar tidak menguntungkan jika penggunaan metode variasinya tidak tepat.

Perkembangan teknologi dan informasi memiliki pengaruh yang siginifikan terhadap manusia. Salah satu dampak yang terasa dari perkembangan teknologi dan informasi yaitu perkembangan dalam dunia pendidikan. Adanya perkembangan teknologi dan informasi dalam dunia pendidikan mengakibatkan perubahan interaksi antara guru dan siswa, hal ini juga berhasil mendigitalisasi bahan ajar dalam dunia pendidikan. Perkembangan teknologi dalam dunia pendidikan juga berperan sebagai alat kolaborasi untuk mengakses bahan ajar dan informasi terkait dengan kegiatan pembelajaran. Kemajuan teknologi saat ini 
diharapkan dapat memberikan kemudahan dalam dunia pendidikan terkait dengan kegiatan proses pembelajaran. Proses pembelajaran ini dilakukan oleh guru dan siswa dengan alat bantu berupa bahan ajar yang didalammya memuat berbagai informasi. Informasi yang dimaksud yaitu berupa serangkaian materi yang sesuai dengan kurikulum yang sedang diterapkan. Bahan ajar sendiri diartikan oleh Majid (2011) bahwa bahan ajar sebagai segala bentuk bahan yang digunakan untuk membantu guru dalam melaksanakan kegiatan belajar mengajar baik berupa bahan yang tertulis maupun bahan tidak tertulis. Melalui bahan ajar ini guru dan siswa dihadapkan pada tujuan pembelajaran. Contoh dari bahan ajar yaitu seperti buku, modul, lembar kerja siswa, dll. Dari beberapa contoh tersebut tergambarkan bahwa bahan ajar itu berbentuk cetak (printed). Namun dengan adanya perkembangan teknologi saat ini, bahan ajar tidak berbentuk cetak lagi melainkan dalam bentuk digital. Teknologi digital ini erat kaitannya dengan penggunaan komputer/laptop/ notebook/internet dan alat-alat digital pendukungnya. Menurut Weaver \& Nilson (2005), perangkat digital seperti laptop/notebook mempunyai berbagai fungsi yang sangat penting bagi pembelajaran di kelas.

Di era modern ini, sangat tepat jika disediakan bahan pembelajaran yang sesuai dengan kemajuan Ilmu Pengetahuan dan Teknologi (IPTEK) karena pada dasarnya generasi sekarang adalah generasi yang tidak lepas dari perkembangan teknologi. Generasi anak saat ini tergolong sebagai generasi digital native yaitu generasi yang dilingkupi dengan lingkungan berbasis teknologi (Oktavia, 2019). Menurut Santi (2016), digital native membuat siswa setiap harinya berkutat dan dikelilingi oleh komputer, internet, handphone dan smartphone. Oleh karena itu perlu desain bahan pembelajaran yang tepat untuk anak digital native yaitu bahan pembelajaran yang berbasis digital.

Permasalahan yang dihadapi oleh guru SMPN 5 Kendari dan SMP 9 Kendari sebagai mitra pengabdian adalah kurangnya pemanfaatan Teknologi Informasi dan Komunikasi (TIK) dalam kegiatan pembelajaran. Kurang updatenya informasi, tahun kelulusan guru yang belum menyentuh teknologi selama masa perkuliahan dan ketidakterlibatan dalam pelatihan berbasis TIK menjadi faktor utama ketidakmampuan guru dalam mengembangkan bahan ajar digital berbasis TIK. 
Ketidakseriusan guru dalam memperhatikan kemajuan teknologi akan menyebakan dirinya akan semakin tertinggal pengetahuan dalam bidang teknologi. Sementara siswa sekarang ini lebih familiar terhadap penggunaan teknologi, bahakan telah menjadi kebutuhan primer siswa itu sendiri. Oleh karena itu, jika guru tidak mengembangkan kompetensi setiap saat maka bisa jadi pembelajaran di kelas akan berjalan satu arah.

Sejalan dengan perkembangan zaman dan ilmu pengetahuan dan teknologi, bahan pembelajaran juga harus dapat menyesuaikan dengan perkembangan tersebut. Bahan ajar tersebut berbasis digital yang didesain disesuaikan dengan kondisi saat ini dan menarik perhatian peserta didik. Namun, kurangnya pengetahuan guru dalam membuat bahan ajar digital menjadikan kegiatan pelatihan penting untuk dilakukan bagi guru. Pelatihan ini dirancang dalam kegiatan pengabdian kepada masyarakat dengan menggunakan bahan ajar digital berbasis whiteboard animation. Bahan ajar digital ini dirancang dengan menggunakan whiteboard animation dengan memadukan animasi bergerak, alur cerita (konsep materi), dan gambar. Hasil dari pengembangan bahan ajar digital berbasis whiteboard animation berupa video pembelajaran setiap sesion yang selanjutnya diupload di youtube yang dihiperlink menjadi sebuah aplikasi pembelajaran pada sistem android. Sehingga whiteboard animation ini dapat membantu guru dalam menjelaskan materi pelajaran dan siswa juga akan lebih senang dan mudah dalam memahami materi sehingga berdampak pada prestasi belajar siswa yang semakin membaik.

Bahadur \& Oogarah (2013) menyatakan bahwa media interaktif whiteboard sangat efektif digunakan sebagai media pembelajaran di kelas. Kemudian menurut Manny-Ikan, et.al (2011) pembelajaran dengan media interaktif whiteboard menjadikan motivasi siswa lebih baik dan hasil belajar semakin meningkat, guru juga lenih meningkatkan kemampuan dalam mengembangkan pembelajaran. Menurut Akbaş \& Pektaş (2011) pemanfaatan whiteboard animation dalam pembelajaran menjadikan siswa lebih antusias dalam belajar, tingkat partisipasi siswa meningkat dibandingkan dengan pembelajaran biasa, dan juga pemahaman konsep lebih efektif. Koçak \& Gülcü (2013) menyebutkan bahwa pembelajaran 
menggunakan media whiteboard menjadikan guru dapat menyelesaikan kesulitan yang dialami siswa dalam menerima meteri pelajaran.

Pemecahan masalah sebagai solusi yang ditawarkan dalam kegiatan ini yaitu perlunya pelatihan dan pendampingan bagi sekolah mitra SMP Negeri 5 Kendari maupun SMP Negeri 9 Kendari mengenai pengembangan bahan ajar digital dengan menggunakan whiteboard animation. Manfaat dari pelatihan ini akan dirasakan langung oleh guru SMP mitra dalam mengembangkan dan menerapkan media pembelajaran yang didesain dalam kegiatan pelatihan. Pelaksanaan pengabdian kepada masyarakat ini dilakukan untuk mendukung upaya pengembangan kualitas pembelajaran yang kreatif dan menyenangkan serta meningkatkan kompetensi guru dibidang TIK yang ditujukan kepada sekolah mitra berupa pelatihan pengembangan bahan ajar digital dengan whiteboard animation.

\section{METODE}

Tahapan dalam pelaksanaan kegiatan pengabdian kepada masyarakat ini meliputi: (a) tahapan persiapan meliputi melakukan Focus Group Discussion (FGD) pada tim pengabdian kepada masyarakat, melakukan koordinasi dengan pihak sekolah mitra, menetapkan waktu dan lokasi sekolah pelaksanaan kegiatan pelatihan; (b) tahapan pelaksanaan pelatihan pengembangan bahan ajar digital menggunakan whiteboard animation meliputi pemberian pengetahuan dasar tentang aplikasi whiteboard animation, pemilihan materi pokok pembelajaran yang dapat memanfaatkan aplikasi whiteboard animation, serta cara pembuatan bahan ajar digital yang memanfaatkan aplikasi whiteboard animation; (c) tahapan pendampingan kepada para peserta pelatihan, dalam rangka pemahaman dan aplikasi pengetahuan dan keterampilan dalam mengembangkan bahan ajar digital menggunakan aplikasi whiteboard animation, merancang bahan ajar digital yang menarik, interaktif dan menyenangkan dengan memanfaatkan aplikasi whiteboard animation (mulai dari perencanaan, proses pemilihan materi, dan penggunaan aplikasi whiteboard animation, (d) tahapan monitoring dalam pelaksanaan kegiatan melalui motivasi pada para guru yang sudah dapat menggunakan aplikasi 
whiteboard animation untuk keperluan pengembangan bahan ajar digital sehingga bisa konsisten dan tetap bersemangat untuk terus mengembangkannya.

Metode yang digunakan selama proses pelaksanaan kegiatan pengabdian kepada masyarakat meliputi: (1) metode ceramah untuk memberikan penjelasan langsung pengembangan bahan ajar digital menggunakan whiteboard animation, (2) metode diskusi untuk curah pendapat antara peserta dengan tim pengabdian pada hal-hal yang dianggap sulit, (3) metode praktek untuk memberikan kesempatan kepada peserta mempraktekan materi pelatihan yang diperoleh.

Peserta kegiatan pengabdian ini adalah guru SMP Negeri 5 Kendari dan SMP Negeri 9 Kendari sebanyak 20 orang. Guru SMP Negeri 5 Kendari yang terlibat sebanyak 12 orang dengan rincian yaitu 2 orang guru matematika, 2 orang guru IPA, 2 orang guru prakarya, 1 orang guru PPKn, 1 orang guru pendidikan olahraga, 2 orang guru seni budaya, 1 orang guru pendidikan agam aislam $\&$ budi pekerti dan 1 orang guru IPS. Guru SMP Negeri 9 Kendari yang terlibat sebanyak 8 orang dengan rincian yaitu 4 orang guru matematika, 1 orang guru bahasa indonesia, 1 orang guru bahasa inggris, 1 orang guru IPA, dan 1 orang guru IPS. Kegiatan pelatihan ini dilaksanakan di Ruangan Laboratorium Komputer SMP Negeri 5 Kendari dengan alamat sekolah berada pada Jl. Gersamata, Kelurahan Anduonohu Kecamatan Poasia Kota Kendari Provinsi Sulawesi Tenggara.

Indikator keberhasilan pelaksanaan kegiatan pengabdian kepada masyarakat ini adalah: (1) adanya pengetahuan dan wawasan guru-guru pada sekolah mitra terhadap konsep bahan ajar digital dan aplikasi whiteboard animation yang diukur dari produk yang dihasilkan, (2) evaluasi keseluruhan pelaksaaan kegiatan pelatihan minimal telah tercapai sebanyak minimal $80 \%$.

\section{HASIL DAN PEMBAHASAN}

Sebelum pelaksanaan kegiatan pengabdian kepada masyarakat tim pengabdian melakukan Focus Group Discussion (FGD) untuk mematangkan dan menentukan konten pelatihan yang akan diajarkan kepada peserta. Tahapan selanjutnya melakukan koordinasi denga pihak sekolah untuk mengirimkan peserta untuk mengikuti kegiatan pelatihan pengembangan bahan ajar digital 
menggunakan whiteboard animation pada guru SMP. Terdapat dua sekolah mitra dalam kegiatan pelatuhan ini yaitu SMP Negeri 5 Kendari dan SMP Negeri 9 Kendari serta lokasi pelaksanaan kegiatan pengabdian terpusat di SMP Negeri 5 Kendari.

Kegiatan pengabdian kepada masyarakat ini dilaksanakan selama dua hari mulai tanggal 16 November-17 November 2019. Kegiatan pengabdian ini diikuti oleh 20 orang guru yang berasal dari SMP Negeri 5 Kendari dan SMP Negeri 9 Kendari dari berbagai disiplin ilmu yang berbeda. Guru ini direkomendasikan oleh Kepala Sekolah dengan memertimbangkan tingkat kemampuan guru mengoperasikan laptop.

Pada pelaksanaan kegiatan pengabdian, terlebih dahulu guru diberikan pengantar materi tentang pengetahuan dasar aplikasi whiteboard animation. Guru dibimbing untuk melakukan instalasi software aplikasi videoscribe kemudian memperkenalkan fitur-fitur yang dimilikinya serta cara mengembangkan kontennya agar dapat menjadi bahan ajar digital berbasis whiteboard animation.

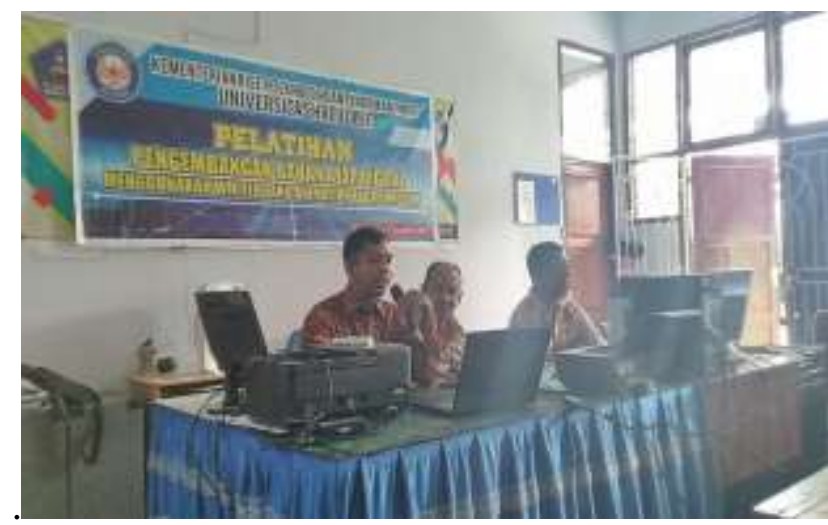

\section{Gambar 1. Penyampaian Materi Pelatihan Oleh Tim Pengabdian}

Aplikasi videoscribe adalah sebuah program aplikasi atau software yang dapat dipergunakan untuk membuat presentasi video, dengan animasi tangan bergerak pada sebuah papan atau white board sehingga dikenal dengan nama whiteboard animation. Animasi tangan ini dapat seirama dengan objek berupa teks atau gambar yang ditampilkan pada layar, sehingga bila dilihat seperti tangan sipembuat sendiri yang melakukannya. Keunikan dari videoscribe terletak pada 
penjelasan suatu topik dengan media gambar dan tulisan yang ditulis atau digambar.

Setelah kegiatan penyampaian materi selesai, maka selanjutnya guru didampingi oleh tim pengabdian. Pendampingan berfokus pada pembuatan dan pengembangan bahan ajar digital dengan menggunakan whiteboard animation dengan harapan guru mampu membuat sendiri dan memiliki media pembelajaran dengan memanfaatkan whiteboard animation. Guru-guru yang terlibat dalam kegiatan pelatihan dan pendampingan pengembangan bahan ajar digital dengan whiteboard animation dibentuk secara berkelompok sehingga pewakilan pada setiap mata pelajaran terpenuhi.

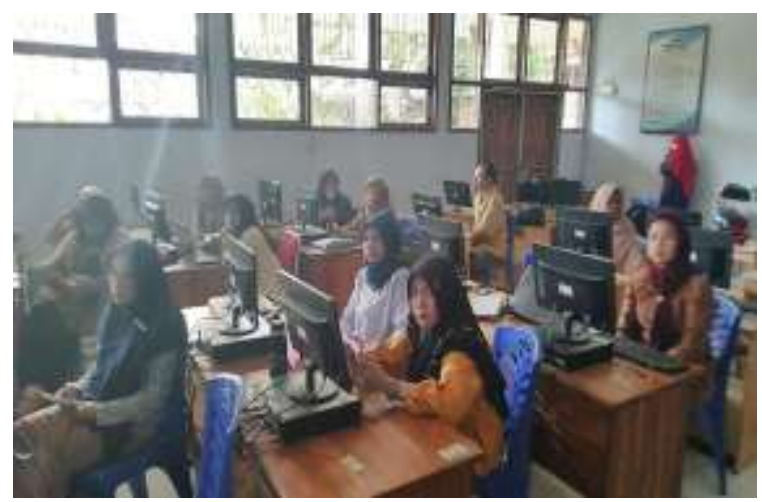

\section{Gambar 2. Kegiatan Pendampingan Peserta dalam Membuat Whiteboard Animation}

Guru yang mengikuti kegiatan pengabdian diberi tugas untuk membuat bahan ajar digital dengan menggunakan whiteboard animation sesuai dengan bidang studi yang diampuhnya yang didampingi oleh tim pengabdian. Setelah kegiatan pendampingan selesai tampak bahwa sebagian besar peserta sudah menghasilkan sebuat project whiteboard animation dengan menggunakan aplikasi Videoscribe. 


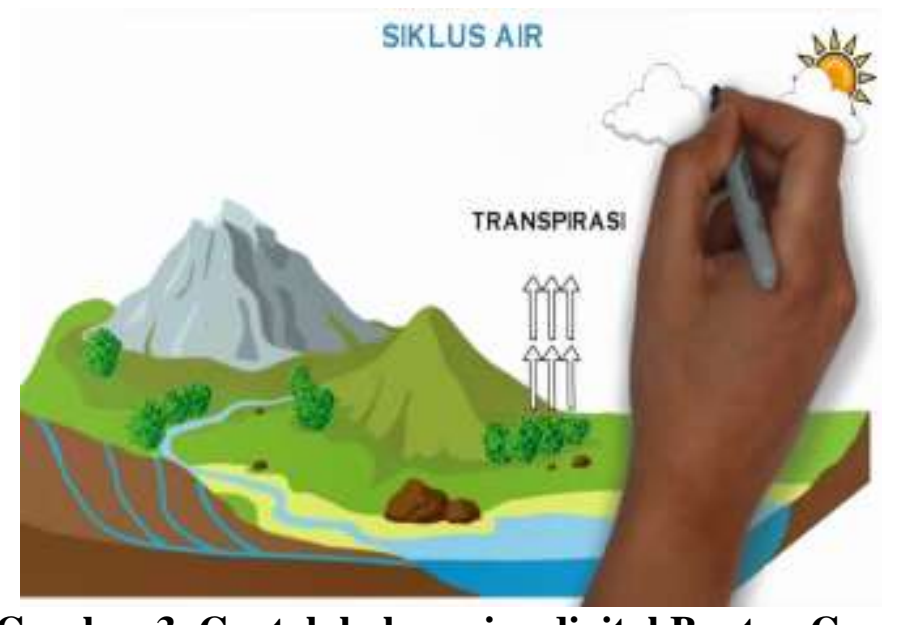

Gambar 3. Contoh bahan ajar digital Buatan Guru

Evaluasi pelaksanaan kegiatan pengabdian dilakukan mulai tahap pemberian materi sampai pada pendampingan untuk membuat project media pembelajaran dihasilkan guru dengan hasil evaluasi pelaksanaan tersaji pada Tabel 1 berikut.

Tabel 1. Hasil Evaluasi terhadap peserta pelatihan

\begin{tabular}{clc}
\hline No & \multicolumn{1}{c}{ Aspek } & Persentase \\
\hline 1 & $\begin{array}{l}\text { Penguasaan guru terhadap konsep pengembangan bahan ajar } \\
\text { digital menggunakan aplikasi whiteboard animation }\end{array}$ & $86 \%$ \\
\hline 2 & $\begin{array}{l}\text { Penguasaan guru terhadap penggunaan aplikasi whiteboard } \\
\text { animation }\end{array}$ & $88 \%$ \\
\hline 3 & $\begin{array}{l}\text { Desain media pembelajaran dengan menggunakan aplikasi } \\
\text { whiteboard animation menarik minat siswa }\end{array}$ & $85 \%$ \\
\hline & $\begin{array}{l}\text { Bahan ajar digital menggunakan aplikasi whiteboard } \\
\text { animation yang dihasilkan guru dapat dijalankan dengan } \\
\text { baik }\end{array}$ & $89 \%$ \\
\hline 5 & $\begin{array}{l}\text { Partisipasi guru selama pelatihan dan pendampingan dalam } \\
\text { pengembangan bahan ajar digital menggunakan aplikasi } \\
\text { whiteboard animation }\end{array}$ & $95 \%$ \\
\hline
\end{tabular}

Hasil evaluasi guru pada penguasaan konsep dan tingkat kemampuan dalam pengembangan bahan ajar digital menggunakan aplikasi whiteboard animation menunjukkan hasil yang sangat bagus. Selain itu, guru juga memberikan respon positif terhadap kegiatan pengabdian ini, sebab bahan pelatihan telah memberikan tambahan pengetahuan untuk media pembelajaran yang dapat digunakan dalam proses pembelajaran, serta harapan agar kegiatan pengabdian seperti ini terus dikembangkan. 


\section{SIMPULAN}

Berdasarkan hasil yang dicapai pada kegiatan ini, disimpulkan bahwa: (1) para peserta pelatihan telah memiliki pengetahuan membuat bahan ajar digital menggunakan whiteboard animation, (2) para peserta pelatihan telah memiliki bahan ajar digital dengan menggunakan whiteboard animation, (3) para peserta pelatihan telah memiliki pengetahuan dalam membuat dan mengembangkan konten bahan ajar digital menggunakan whiteboard animation .

Saran yang dapat diberikan terkait hasil dari kegiatan ini yaitu: (1) para peserta diharapkan untuk membuat dan mengembangkan konten bahan ajar digital menggunakan whiteboard animation lebih lanjut lagi agar pembelajaran lebih menarik, inovatif, dan interaktif, (2) pembuatan bahan ajar digital menggunakan whiteboard animation ini dapat dijadikan sebagai referensi untuk menunjang kegiatan pembelajaran pada Sekolah Menengah Pertama, dan (3) Lembaga Sekolah Menengah Pertama lainnya yang tidak terlibat dalam kegiatan pelatihan ini dapat menggunakan whiteboard animation dalam membuat dan mengembangkan bahan ajar digital di lembaganya.

\section{UCAPAN TERIMA KASIH}

Ucapan terima kasih yang mendalam kepada Lembaga Penelitian dan Pengabdian Kepada Masyarakat (LPPM) Universitas Halu Oleo yang telah mendukung dan membiayai pelaksanaan kegiatan pengabdian sehingga dapat terlaksana sesuai jadwal yang tekah ditetapkan.

\section{DAFTAR PUSTAKA}

Akbaş, O., \& Pektaş, H. M. (2011). The effects of using an interactive whiteboard on the academic achievement of university students. In Asia-Pacific Forum on Science Learning and Teaching, 12(2), 1-19.

Bahadur, G. K., \& Oogarah, D. (2013). Intercative whiteboard for primary school in mathematic an effective tool or just another trend?. International Journal of Education and Development using Information and Communication Technology (IJEDICT), 9(1), 19-35.

Budiwibowo, S. (2016). Hubungan minat belajar siswa dengan hasil belajar IPS Di SMP Negeri 14 Kota Madiun. Gulawentah: Jurnal Studi Sosial, 1(1), 60-68. http://doi.org/10.25273/gulawentah.v1i1.66. 
Fakhrurrazi. (2018). Hakikat pembelajaran yang efektif. Jurnal At-Tafkir, 11(1), 85-99. https://doi.org/10.32505/at.v11i1.529.

Karina, R.M., Syafrina, A., \& Habibah, S. (2017). Hubungan antara minat belajar dengan hasil belajar siswa dalam mata pelajaran IPA pada kelas V SD Negeri Garot Geuceu Aceh Besar. Jurnal Ilmiah Pendidikan Guru Sekolah Dasar, 2(1), 61-77.

Koçak, Ö., \& Gülcü, A. (2013). Teachers' remarks on interactive whiteboard with LCD panel technology. International Journal of Education in Mathematics Science and Technology, 1(4), 294-300.

Majid, A. (2011). Perencanaan pembelajaran. Bandung: Remaja Rosdakarya.

Manny-Ikan, E., Dagan, O., Tikochinski, T. B., \& Zorman, R. (2011). Using the interactive white board in teaching and learning-an evaluation of the smart classroom pilot project. Interdisciplinary Journal of E-Learning and Learning Objects, 7, 249-273.

Oktavia, S. (2019). Peran perpustakaan dan pustakawan dalam menghadapi generasi digital native. Bibliotika: Jurnal Kajian Perpustakaan Dan Informasi, $\quad 3(1), \quad 81-89, \quad$ (Online), (http://dx.doi.org/10.17977/um008v3i12019p081).

Pane, A., \& Dasopang, M. D. (2017). Belajar Dan Pembelajaran. FITRAH: Jurnal Kajian Ilmu-ilmu Keislaman, 3(2), 333-352, (Online), (https://doi.org/10.24952/fitrah.v3i2.945).

Santi, T. (2016). Peran Sosial Perpustakaan di Era Digital Native. Jurnal Iqra', 10(2), 1-10, (Online), (http://dx.doi.org/10.30829/iqra.v10i02.533).

Weaver, B. E., \& Nilso, L.B. (2005). Notebook in class: what are they good for? what can you do with them?. New Directions in Teaching and Learning, 101, $1-3$. 